\title{
THE EFFECT OF MATMO TYPHOON ON MIXED ZONE BETWEEN THE YELLOW SEA AND BOHAI SEA
}

\author{
Guo Jie ${ }^{1}$, He Yijun ${ }^{2}$, Ji Ling $^{3}{ }^{3}$ Ji Diansheng $^{3}$, Hou chawei ${ }^{3}$, GuoKai ${ }^{1}$,
} Mou Yankai ${ }^{1}$, Li Qingjie ${ }^{3}$, Guo shuang ${ }^{4}$

${ }^{1}$ Key Laboratory of Coastal Zone Environmental Processes, CAS; Shandong Provincial Key

Laboratory of Coastal Zone Environmental Processes; Yantai Institute of Coastal Zone Research, Chinese Academy of Sciences, 17 Chunhui Road, Laishan District,Yantai, 264003, P. R. China. jguo@yic.ac.cn

${ }^{2}$ School of Marine Sciences, Nanjing University of Information Science \& Technology, 219

Ningliu Road, Nanjing, Jiangsu, 210044, China. yjhe@nuist.edu.cn

${ }^{3}$ Yantai Marine Environmental Monitoring Central Station, SOA, 11Ningbo Road, Development Zone District, Yantai 264006, China. houcw1982@163.com

${ }^{4}$ School of electrical and information engineering, Henan University of Urban Construction. Ping Ding Shan City XIn Chen Area Ming Yue Road HeNan Province, 467036, P.R. China 572687748@qq.com

\begin{abstract}
The results of remote sensing, buoy and profile based on measured data indicate that the wind speed, $\mathrm{H}_{1 / 3}$ and salinity increased, sea surface temperature declined, and wind direction changed greatly during the transit of the Matmo typhoon on July 25. It was found that the typhoon transport the Yellow Sea Cold Water Mass into the the Yellow and Bohai seas mixed zone.
\end{abstract}

Index Terms: the Yellow and Bohai seas mixed zone, the Yellow Sea Cold Water Mass, wind speed, buoy data, remote sensing data.

\section{INTRODUCTION ${ }^{1}$}

The Yellow and Bohai seas mixed zone (Y-B) is an ideal breeding base for wildlife, and there are more than 210 types of abundant seafood. There are also more than 320 migratory birds each year and the total number of birds is greater than 1.2 million. Every year this habitat supports nearly 400 Pacific leopard seal. The Y-B is a national nature reserve area and the provincial level nature reserve area of seals.

The two main marine hydrological

${ }^{1}$ Corresponding author: Guo Jie, associate research fellow. Subject: ocean remote sensing. Work at Yantai Institute of Coastal Zone Research, Chinese Academy of Sciences. characteristics of the Yellow Sea are the Yellow Sea Warm Current (YSWC), and the Yellow Sea Cold Water Mass (YSCWM). The YSWC and Yellow Sea (western) flow constitute a cyclone type circulation; it said that it was the circulation of the Yellow Sea. To some extent, the YSWC has the nature of compensation flow: where the winter monsoon has a north-west wind field and the coastal current increase, resulting in a strong YSWC. The coastal rheological is weak due to the SE monsoon in summer, and as a result the YSWC is also weak. The YSWC is mainly limited to the upper mixed layer and the lower layer is limited by the YSCWM (low temperature and high salinity). YSWC has characteristics of strong winter summer weakness. The stronger the YSWC is in winter, the stronger the YSCWM is in summer of next year (Bao et al, 2001).

The Matmo typhoon on July 23, 2014 landed at $0: 15$ on the coast of Taiwan, with a maximum wind speed of $42 \mathrm{~m} / \mathrm{s}$ near the central. The typhoon on July 25, 2014, occurred in the afternoon at 17:10, and changed into a tropical storm, landing at Rongcheng in Shandong province. The 
maximum wind speed near the central maximum was $20 \mathrm{~m} / \mathrm{s}$ (Fig.1a). Here we analyze how the Matmo typhoon affected the Y-B and whether it brought YSCWM into the Bohai Sea.

\section{MATERIALS AND METHODS}

Remote Sensing observations have been widely used in studying typhoons (Friedman and Li 2000; Li et al., 2002; Li et al., 2013; Li et al., 2015) The wind field, significant wave height $\left(\mathrm{H}_{1 / 3}\right)$, sea surface temperature (SST), salinity (SAL) and chlorophyll concentration (CHL) of Y-B were analyzed using Radarsat-2 SAR, MODIS and Buoy1 $\left(37.54{ }^{\circ} \mathrm{N}, 122.01{ }^{\circ} \mathrm{E}\right)$ data. Study area is rectangular region (Guo et al, 2016) located near the Y-B; A $\left(37.5^{\circ} \mathrm{N}, 120^{\circ} \mathrm{E}\right), \mathrm{B}$ $\left(37.5^{\circ} \mathrm{N}, 124^{\circ} \mathrm{E}\right), \mathrm{C}\left(39^{\circ} \mathrm{N}, 124^{\circ} \mathrm{E}\right), \mathrm{D}$ $\left(39^{\circ} \mathrm{N}, 120{ }^{\circ} \mathrm{E}\right)$ (Fig.1b). We applied a statistical analysis method in this paper.

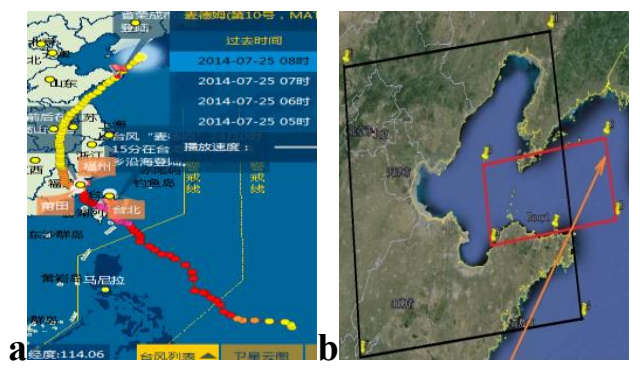

Fig.1 Typhoon path of Matmo (a); and a sketch map of study area (b)

3. DISCUSSIONS

The wind velocity retrieved by Radarsat 2 data (2230) was compared with buoyl data (Table1). The maximum differences in longitude and latitude are $0.15^{\circ}$ and 1 hour in time. We found that wind velocity retrieved from the Radarsat2 real-time data using the C-band Cross-Polarization Ocean Backscatter (C-2PO) model (Zhang et al., 2012) was in a good agreement $(\mathrm{RMS}=1.96 \mathrm{~m} / \mathrm{s})$ with real-time buoyl data (Table1).This shows that the C-2PO model inversion under the high wind speed is effective (Fig.2).
Table1. Wind field inversion by Radarsat 2 data compared with wind field data measured by buoy 1 data (Root mean square-RMS)

\begin{tabular}{|l|l|l|l|l|l|}
\hline $\begin{array}{l}\text { Instru } \\
\text { ment }\end{array}$ & Time & $\begin{array}{l}\text { Latit } \\
\text { ude }\end{array}$ & $\begin{array}{l}\text { Long } \\
\text { itude }\end{array}$ & $\begin{array}{l}\text { Win } \\
\mathrm{d} \\
\text { spee } \\
\mathrm{d}\end{array}$ & $\begin{array}{l}\text { Wind } \\
\text {-Dir }\end{array}$ \\
\hline $\begin{array}{l}\text { Radar } \\
\text { sat2_ } \\
\text { VH }\end{array}$ & $\begin{array}{l}2014.07 . \\
25.64\end{array}$ & $\begin{array}{l}37.54 \\
{ }^{\circ} \mathrm{N}\end{array}$ & $\begin{array}{l}122.0 \\
{ }^{\circ} \mathrm{E}\end{array}$ & $\begin{array}{l}\mathrm{RM} \\
\mathrm{S}=1 .\end{array}$ & $349^{\circ}$ \\
\hline Buoy1 & $\begin{array}{l}2014.07 . \\
25 \_18: 0\end{array}$ & $\begin{array}{l}{ }^{\circ} \mathrm{N} \\
0\end{array}$ & $1^{\circ} \mathrm{E}$ & $3 \mathrm{~m} / \mathrm{s}$ & \\
\hline
\end{tabular}

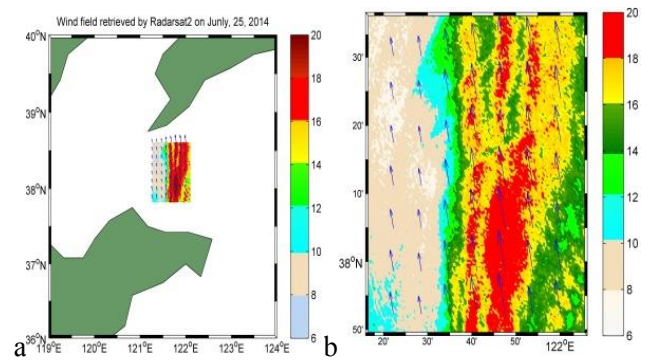

Fig.2 Wind field retrieved by Radarsat 2 data at 18:18.64 on July, 25, 2014

Fig.3 shows that the highest average winds speed was $17.3 \mathrm{~m} / \mathrm{s}$ at $17: 00$ on July, 25 , 2014, and the wind direction varied considerably from 14 to 15 points. $\mathrm{H}_{1 / 3}$ increased gradually to $2.3 \mathrm{~m}$ from $0: 00$ to 19:00, and decreased slowly from 20:00 to 23:00. The SST decreased gradually to $17.82{ }^{\circ} \mathrm{C}$ from $0: 00$ to $10: 00$ and maintained a relatively stable value from 11:00 to 23:00. The SAL had a relatively stable value of 30.00 psu from 0:00 to 7:00, rapidly increased to $30.454 \mathrm{psu}$ from 8:00 to 10:00, and then suddenly decreased to 29.946 psu from 10:00 to 12:00 due to rain. SAL then was increased abruptly to 30.517 psu from 12:00 to 16:00, and then maintains a relatively stable value from 16:00 to 23:00. Overall, SAL had an increasing trend. 
From July 17, to August 2, 2014 (Fig.4), the wind speed, $\mathrm{H}_{1 / 3}$ and SAL increased, SST declined, and wind direction changed greatly during the transit of the Matmo typhoon on July 25. From Fig.5 we can see that the average SST (CHL) in July 2014 was less (more) than that in July from 2004 to 2013 in the study area. The area was significantly affected by the Matmo typhoon, compared with buoyl and remote sensing data.

As the YSWC flowed into Bohai Sea during the winter of 2013 (Guo et al, 2016), the YSCWM would increase in northern Yellow (Jiang et al, 2007), as shown in Fig.6.
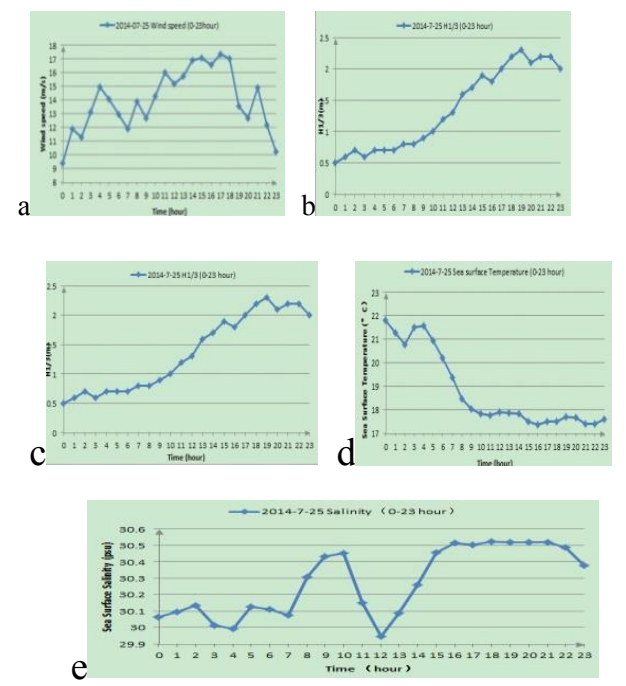

Fig.3 Wind speed (a), wind direction (b); $\mathrm{H}_{1 / 3}(\mathrm{c})$; SST (d); SAL (e) variation between 0 to 23 hours on July, 25, 2014 based on buoyl data
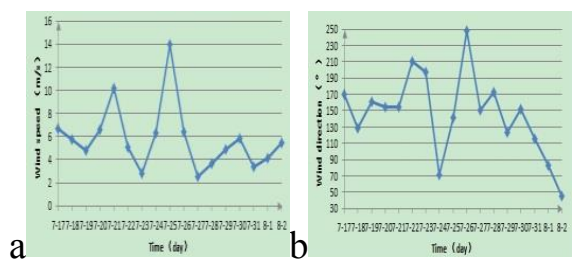

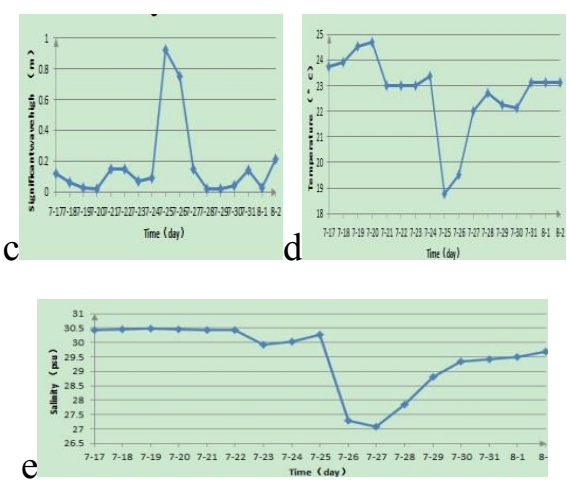

Fig.4 Wind speed (a); wind direction (b); $\mathrm{H}_{1 / 3}(\mathrm{c})$; SST (d); SAL (e) variation from July 17 to August 2, 2014based on buoy1 data
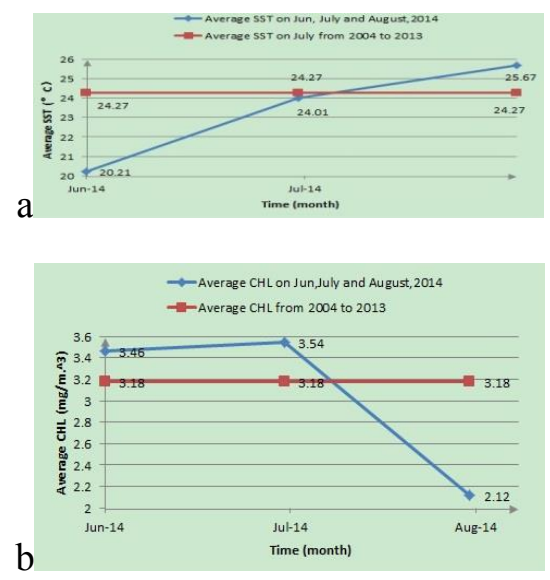

Fig.5 Average SST (CHL) in June, July, and August, 2014 compared with the average SST (CHL) in July from 2004 to 2013(a,b);

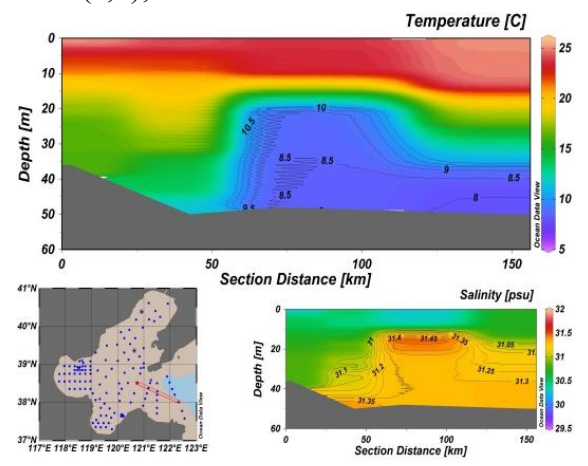

Fig.6 SST and SAL profile based on measured data in Y-B from 12, August to 6, September, 2014

\section{CONCLUSIONS}


Because the maximum wind speed during the Matmo typhoon near center was grade eight $(20 \mathrm{~m} / \mathrm{s})$ in $\mathrm{Y}-\mathrm{B}$, it could transport YSCWM into Y-B (Su et al, 2001). This was one of the most important factors that caused SST cooling (Fig.4d and 5a) on July 25, 2014 and a higher than average CHL in July from 2004 to 2013 (Fig.5b). It also caused an increase in SAL on July, 25, 2014. The inversion layer of SAL in Fig.6, it came from SST and SAL profile measured data in Y-B from August 12 to September 6, 2014, showing the typhoon transporting YSCWM into the $\mathrm{Y}-\mathrm{B}$

\section{ACKNOWLEDGMENTS}

This work was supported by the National Natural Science Foundation of China (No.4141101049, No. 41576032 and No. 41176160) and financially supported by the "Strategic Priority Research Program" of the Chinese Academy of Sciences (No. XDA01020304). We acknowledge the SOAR-EI Project RADARSAT-2 Data and Products MacDonald,Dettwiler and Associates Ltd. (year of acquisition from June, 2014 to June, 2016) - All Rights Reserved. RADARSAT is an official trademark of the Canadian Space Agency.

\section{REFERENCES}

Bao Xianwen, Wang Cizhen,GAO Guoping, and Hung Lei, "Thermal structural analysis and simulation of the Bohai Sea and the Huanghai Seas," Acta Oceanologica Sinica, 23 (6): 24-31, 2001.

Friedman, K. and Xiaofeng Li, Storm patterns over the ocean with wide swath SAR, Johns Hopkins University Applied Physics Lab Technical Digest, Vol. 21, No.1, 80-85, 2000.

Jie Guo, Hua Zhang, Tingwei Cui, Yijun He, Jie Zhang, Kai Guo, Chawei Hou, and Rongjie Liu, "Remote Sensing Observations of the Winter Yellow Sea
Warm Current Invasion into the Bohai Sea, China," Advances in Meteorology, Volume, Article ID 8170296, 10 pages 2016.

http://dx.doi.org/10.1155/2016/8170296. Jiang Peijie, Bao Xianwen, Wu Dexing, Xu Jianping, "Interannual variation of temperature and salinity of northern Huanghai Sea Cold Water Mass and its probable cause," ACTA OCEANOLOGICA SINICA, 29 (4):1-10, 2007.

Li, Xiaofeng, W. Pichel, M. He, S. Wu, K. Friedman, P. Clemente-Colon, C. Zhao, "Observation of Hurricane-Generated Ocean Swell Refraction at the Gulf Stream North Wall with the RADARSAT-1 Synthetic Aperture Radar, "IEEE Transactions on Geoscience and Remote Sensing, Vol. 40, No. 10, 2131-2142, 2002.

Li, Xiaofeng, J. A. Zhang, X. Yang, W. G. Pichel, M. DeMaria, D. Long, and Z. Li, "Tropical cyclone morphology from spaceborne synthetic aperture radar," Bulletin of the American Meteorological Society, doi:10.1175/BAMS-D-11-00211.1, 2013.

Li, Xiaofeng, The First Sentinel-1 SAR Image of a Typhoon, Acta Oceanologica Sinica, 34 (1): 1-2, doi: 10.1007/s13131015-0589-8, 2015.

Su Jie, Li Lei, Bao Xianwen, Gao Guo ping, "Numerical Experiment of SST Response to Typhoon Process in Yellow Sea and Bohai Sea," JOURNAL OF OCEAN UNIV ERSITY OF QINGDAO, 31(2): 165-172, 2001.

Zhang Biao, William Perrie, "Cross-Polarized Synthetic Aperture Radar: A New Potential2 Measurement Technique for Hurricanes," Bulletin of the American Meteorological Society, 93, 531-541, 2012. 